\title{
Controllable biosynthesis of silver nanoparticles using actinobacterial strains
}

https://doi.org/10.1515/gps-2018-0070

Received March 29, 2018; accepted July 20, 2018; previously published online September 3, 2018

Abstract: We report the effect of various parameters, namely substrate concentration, time, $\mathrm{pH}$ and temperature, on the biosynthesis of silver nanoparticles (AgNPs) by using the extract of actinobacterial strains, which were isolated from the sediments of Lonar Crater Lake in India. It was found that the formation of AgNPs and its morphology depended on synthesis conditions. Visual observation of the reaction mixture, ultraviolet-vis spectroscopic analysis and mass of synthesized AgNPs indicated that $25^{\circ} \mathrm{C}, \mathrm{pH} 7$ and 3 days of incubation time were optimal for its efficient synthesis. The transmission electron microscopy (TEM) analysis revealed aggregation and irregular shape of AgNPs both at acidic $\mathrm{pH}$ and below $25^{\circ} \mathrm{C}$. It was found that alkaline $\mathrm{pH}$ and temperature higher than optimal fostered the formation of nanoparticle aggregates. Based on the obtained results, it was concluded that the efficiency of biological synthesis by using actinobacteria as well as the size and shape of fabricated nanoparticles can be manipulated by controlled conditions of synthesis process. The use of desired nanoparticles increases its potential for medical applications.

Keywords: actinobacteria; AgNPs; biological synthesis; $\mathrm{pH}$; synthesis conditions; temperature.

\section{Abbreviations}

$\begin{array}{ll}\text { AgNPs } & \text { silver nanoparticles } \\ \text { ISP2 } & \text { yeast extract-malt extract medium }\end{array}$

*Corresponding author: Patrycja Golinska, Department of Microbiology, Nicolaus Copernicus University, Lwowska 1, 87100 Torun, Poland, e-mail: golinska@umk.pl. https://orcid.org/00000001-9154-8191

Magdalena Wypij, Magdalena Świecimska and Hanna Dahm: Department of Microbiology, Nicolaus Copernicus University, Lwowska 1, 87100 Torun, Poland

Mahendra Rai: Nanobiotechnology Laboratory, Department of Biotechnology, SGB Amravati University, Amravati-444602, Maharashtra, India

Ә Open Access. (लc) BY () 2019 Walter de Gruyter GmbH, Berlin/Boston

\author{
NPs nanoparticles \\ SCA starch casein agar \\ SPR surface plasmon resonance
}

\section{Introduction}

Nanotechnology is a fast-growing branch of science that deals with the synthesis and development of different nanomaterials [1]. Silver nanoparticles (AgNPs) are the main focus of intensive study because of their wide applications, such as catalysts, optics, antimicrobials, anticancer agents, and for biomaterial production [1-4]. There is enormous interest in metal nanoparticles (NPs) because of their unique physical and chemical properties revealed at the nanoscale level [5].

The microbial recovery of noble metals with the formation of their NPs is a green alternative to physical and chemical methods, which use high amounts of energy or toxic solvents and reagents. A biological synthesis process provides a wide range of environmentally acceptable methodology, low-cost production and minimum time required [6].

The biosynthesis of AgNPs using various bacteria, fungi and plants is already well documented [7-11]. However, the exploration of actinomycetes has recently gained interest for efficient biological synthesis of metallic NPs [6].

The bio-fabrication of NPs, which is a "bottom-up" approach, as well as the shape, size, distribution and composition of NPs, depends upon physicochemical properties such as temperature, time, $\mathrm{pH}$, concentration of the substrate and the presence of biomolecules acting as reducing agents (amino acids, proteins, vitamins) and enzyme sources [12-19]. NPs of desired shape and size can be obtained by controlling the above physical and chemical parameters, which influence the rate of nucleation, growth and atomic/molecular precursor [15, 20]. Hence, the demand for the controllable synthesis of NPs is growing day by day.

In the present study, the effect of substrate concentration, time, temperature and $\mathrm{pH}$ on the synthesis, morphology, size distribution and surface charge of AgNPs synthesized from actinobacterial strains was evaluated. 


\section{Materials and methods}

\subsection{Actinobacterial strains}

Four actinobacterial strains (OT1, OF1, OF2 and IF19) were isolated from the sediments of Lonar Crater located in Buldhana district, Maharashtra, India, by the dilution plate procedure described by Rathod et al. [21] on the starch casein agar [22] supplemented with 5\% (w/v) sodium chloride $(\mathrm{NaCl})$, at $\mathrm{pH}$ 8.5. The identification of actinobacterial strains to the closest phylogenetic neighbors based on the nucleotide sequence analysis of $16 \mathrm{~S}$ rRNA gene was made according to method described previously by Golińska et al. [23] and Rathod et al. [21].

In the preliminary studies, the growth of actinobacterial strains for the synthesis of AgNPs was previously estimated by using different media, namely starch casein broth [22], yeast extract-malt extract broth (ISP2) [24] and halophilic nutrient broth [25], all with 5\% $\mathrm{NaCl}$ $(\mathrm{w} / \mathrm{v})$ and $\mathrm{pH}$ 8.5. The most abundant growth of actinobacterial strains was recovered in halophilic nutrient broth, which was further used for the cultivation of actinobacteria.

\subsection{Effect of temperature and time on the formation of AgNPs using actinobacterial strains}

The biosynthesis protocol of AgNPs was described in detail by Golińska et al. [23], Rathod et al. [21] and Wypij et al. [26]. Briefly, actinobacterial strains grew in halophilic nutrient broth [25] for 7 days at $26^{\circ} \mathrm{C}$. The bacterial biomass was then collected by centrifugation $(6000 \times \mathrm{g}$ for $10 \mathrm{~min}$ ) and washed thrice with sterile, distilled water. Cell pellet was then resuspended in sterile, distilled water for 3-day autolysis at $25^{\circ} \mathrm{C}$. The supernatant, after centrifugation at $6000 \times \mathrm{g}$ for $15 \mathrm{~min}$, was combined with silver nitrate $\left(\mathrm{AgNO}_{3}\right.$; final concentration $\left.0.001 \mathrm{~mol} \mathrm{l}^{-1}\right)$ and incubated for 3 days at different temperatures of 10, 15, 20, 25 and $35^{\circ} \mathrm{C}\left( \pm 2^{\circ} \mathrm{C}\right)$ for 3 days in the darkness. The formation of AgNPs was monitored visually at the interval of $24 \mathrm{~h}$ by color change of the reaction mixture from colorless to yellowish-brown and ultraviolet (UV)visible spectroscopy (Nano Drop ND2000, Thermo Scientific, USA) in a wavelength range of 200-800 $\mathrm{nm}$. The efficiency of AgNP synthesis was evaluated based on their dry mass ( $\mathrm{mg} 100 \mathrm{ml}^{-1}$ ). Meanwhile, the effect of time on the synthesis of AgNPs synthesized from actinobacterial strains was recorded at the interval of $24 \mathrm{~h}$ up to 7 days.

A final concentration of $\mathrm{AgNO}_{3}$ of $0.003 \mathrm{~mol} \mathrm{l}^{-1}$ was also used for the synthesis of biogenic AgNPs. However, the use of higher concentration of $\mathrm{AgNO}_{3}$ demonstrated an inhibitory effect on the synthesis of AgNPs.

\subsection{Effect of $\mathrm{pH}$ on the formation of AgNPs}

The actinobacterial strain was cultivated as described above. An autolysis of cell biomass was made by suspending the cells in sterile, distilled water of different $\mathrm{pH}(4,5,6,7$ and 8$)$ and incubated at $25^{\circ} \mathrm{C}$ for 3 days. The $\mathrm{pH}$ of distilled water was set up at 4, 5, 6, 7 and 8 with sterile $0.2 \mathrm{~mol} \mathrm{l}^{-1} \mathrm{HCl}$ and $0.2 \mathrm{~mol} \mathrm{l}^{-1} \mathrm{NaOH}$ using a pH meter (Hanna), sterilized by filtration and used for testing. After autolysis, the cell biomass was centrifuged $(6000 \times \mathrm{g}, 10 \mathrm{~min})$ and the supernatant was combined with silver nitrate (final concentration of $0.001 \mathrm{~mol} \mathrm{l}^{-1}$ ).
The reaction mixture was then incubated for 3 days in the darkness. Visual observations and UV-vis spectroscopy analysis of the biosynthesized AgNPs were performed.

The autolysis of actinobacteria was also performed in the buffers, namely citrate and phosphate, to maintain appropriate $\mathrm{pH}$ value $(4,5,6,7$, and 8). However, the use of buffers had an inhibitory effect on AgNP synthesis.

The physical properties of AgNPs biosynthesized under various conditions of $\mathrm{pH}$ and temperature were estimated for AgNPs from the OT1 strain.

\subsection{Transmission electron microscopy analysis}

The size and morphology of the AgNPs from Nocardiopsis valliformis OT1 actinobacterial strain, synthesized in different $\mathrm{pH}$ and temperatures, were analyzed by using transmission electron microscopy (TEM) (FEI Tecnai F20 X-Twintool, Fei, Hillsboro, OR, USA) operating at an acceleration voltage of $100 \mathrm{kV}$. The samples for analysis were prepared by dropping a small amount of solution of AgNPs on a carbon-coated copper grid ( $400 \mu \mathrm{m}$ mesh size). The samples were then allowed to dry at room temperature prior to measurements. The obtained data were assessed by Statistica Software (StatSoft, USA).

\subsection{Nanotracking analysis}

The average particle size and size distribution of AgNPs synthesized from $N$. valliformis OT1 strain were analyzed by using a nanotracking analysis (NTA) system LM20 (NanoSight Ltd., UK) after AgNP dilution with the nuclease-free water. $0.5 \mathrm{ml}$ of the sample was injected into the sample chamber and observed through LM20.

\subsection{Zeta potential analysis}

The surface charge of AgNPs synthesized from $N$. valliformis OT1 was evaluated in a colloidal suspension of AgNPs by zeta potential measurement. The NP liquid sample was diluted 10 times with water and sonicated at $20 \mathrm{~Hz}$ for $15 \mathrm{~min}$ (Sonic Ruptor 250, Omni International, USA) to break down NP aggregates. The mixture was then filtered through a $0.22-\mu \mathrm{m}$ millipore filter and analyzed by using Malvern Zetasizer 90 (ZS 90; Malvern Instruments Ltd., Malvern, UK).

\section{Results}

\subsection{Molecular identification of actinobacte- rial strains}

Nearly complete $16 S$ rRNA gene sequences $(1412,1418,1413$ and 1402 nt) of OT1, OF1, OF2 and IF19 strains, respectively, were determined. Based on the EzBioCloud analysis [27], OT1 strain was most closely related to $N$. valliformis DSM 
$45023^{\mathrm{T}}(99.4 \%)$ as previously described by Rathod et al. [21]. Isolates OF1 and OF2 were found to be most closely related to Streptomyces palmae CMU-AB204 ${ }^{\mathrm{T}}$ (98.23 and 98.17\%, respectively), while strain IF19, to Streptomyces alkaliphilus DSM 42118 ${ }^{\mathrm{T}}$ (99.71\%).

\subsection{Effect of time, temperature and $\mathrm{pH}$ on the formation of AgNPs}

The absorption spectra of AgNPs biosynthesized after various incubation times are presented in Figure 1, those biosynthesized at various temperatures $(10,15,20,25,35)$, in Figure 2, while those synthesized at different $\mathrm{pH}(4,5$, $6,7,8)$, in Figure 3.

Time, $\mathrm{pH}$ and temperature were found to influence AgNP synthesis significantly. With the increase in duration of synthesis, temperature and $\mathrm{pH}$, the reduction of silver salt was enhanced, as indicated by a change in the color intensity of the experimental samples (Figures 1-3).

The effects of time on the synthesis of AgNPs using N. valliformis OT1, S. palmae OF1 and OF2 and also S. alkaliphilus IF19 strains were studied visually and by UV-vis spectroscopy at an interval of $24 \mathrm{~h}$. The color change in the reaction mixture and specific absorbance peaks in the range of 380-450 nm were observed after 48 and $72 \mathrm{~h}$ of incubation at $25^{\circ} \mathrm{C}$. Moreover, absorption peak intensity increased with the increase in duration of biosynthesis process as a result of the continuous formation of AgNPs in the reaction system. The optimum time required for the completion of synthesis was found to be $72 \mathrm{~h}$ (Figure 1). Further extension of incubation time (up to 7 days) did not affect the synthesis process.

Generally, a broad peak of less intensity was observed after analysis of AgNPs synthesized at lower temperatures $\left(10,15\right.$ and $\left.20^{\circ} \mathrm{C}\right)$. With an increase in temperature value to $25^{\circ} \mathrm{C}$, the surface plasmon resonance (SPR) peaks (at wavelength about $400 \mathrm{~nm}$ ) became sharper, which suggests that this temperature is optimal for the biosynthesis of AgNPs. Biosynthesis at a higher temperature $\left(35^{\circ} \mathrm{C}\right)$ affected lower intensity peaks for AgNPs from OF1, OF2 and IF19 strains but not from OT1, which was similar to that recorded at $25^{\circ} \mathrm{C}$ (Figure 2).

The highest intensity of absorbance peaks was observed for AgNPs synthesized at alkaline $\mathrm{pH}$, namely 7 and/or 8 (Figure 3).

The bands were observed in the wavelength range of 380-450 nm, which is typical for AgNPs (Figures 1-3).

Moreover, the efficiency of AgNP synthesis from $N$. valliformis OT1 strain after various incubation periods
A
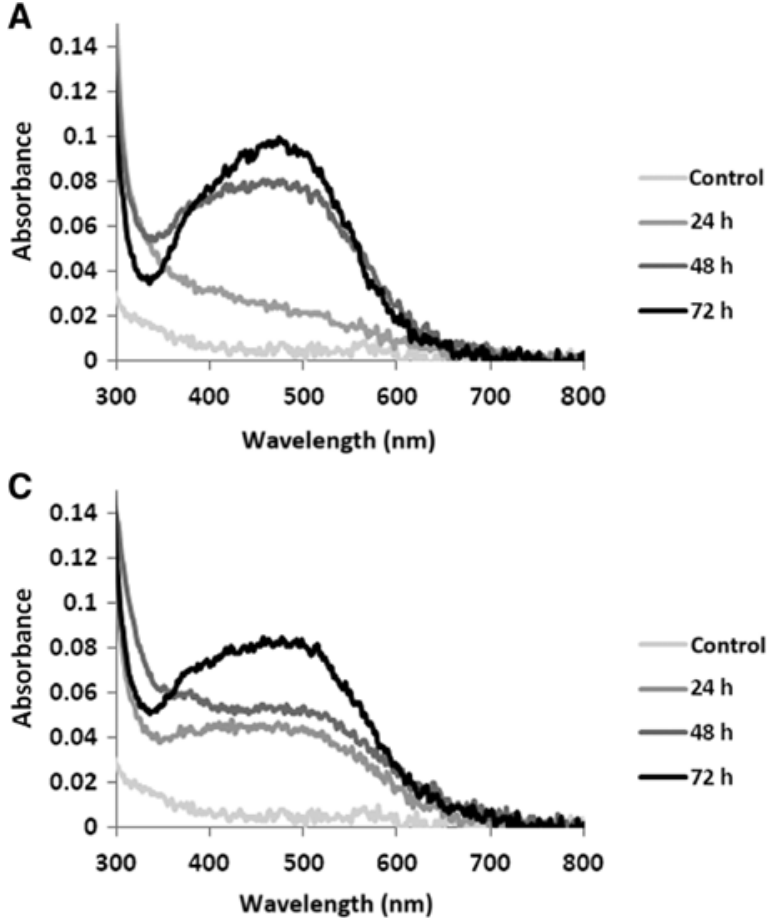

B
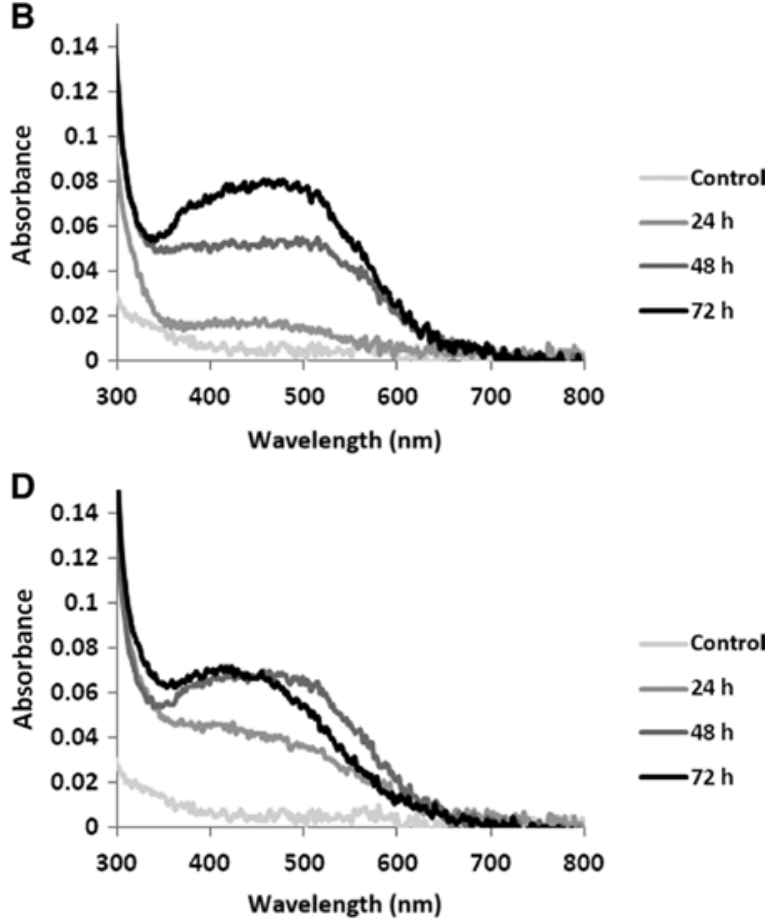

Figure 1: The absorption spectra of AgNPs biosynthesized after incubation time (24, 48 and 72 h) by N. valliformis OT1, S. palmae OF1, OF2 and also S. alkaliphilus IF19 strains. N. valliformis OT1 strain (A); S. palmae OF1 strain (B); S. palmae OF2 strain (C); S. alkaliphilus IF19 strain (D). 

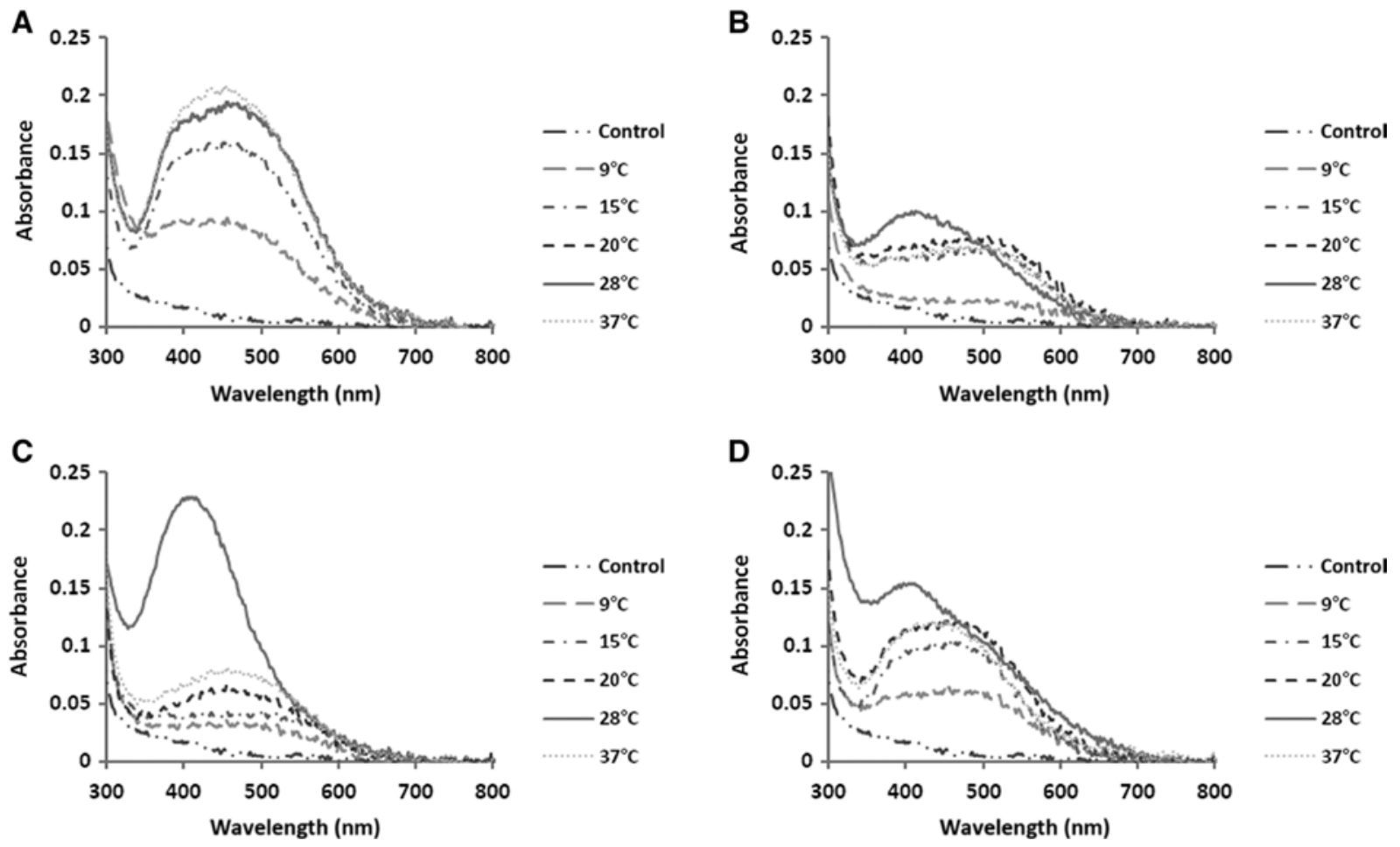

Figure 2: The absorption spectra of AgNPs biosynthesized under various conditions of temperature. N. valliformis OT1 strain (A); S. palmae OF1 strain (B); S. palmae OF2 strain (C); S. alkaliphilus IF19 strain (D).
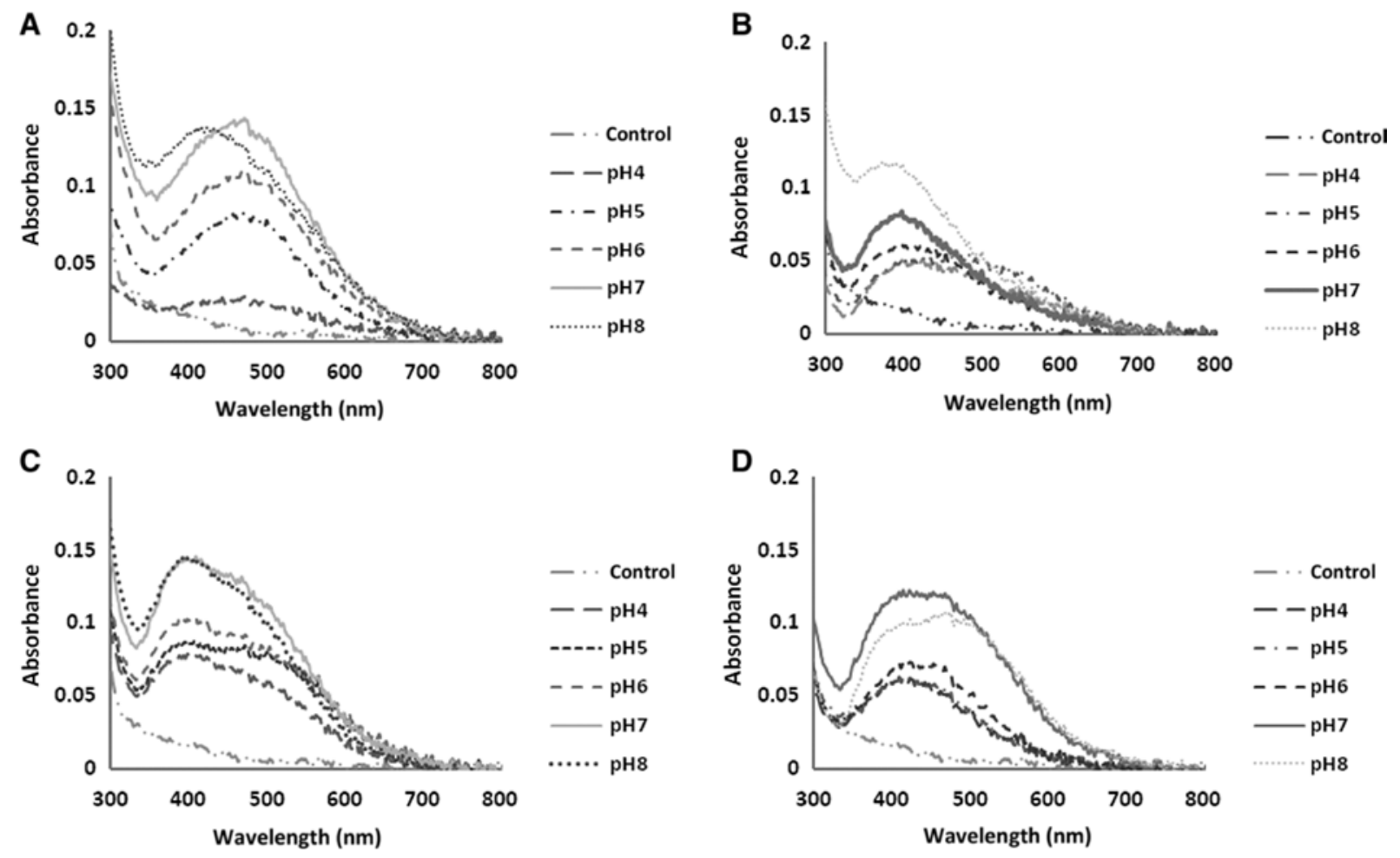

Figure 3: The absorption spectra of AgNPs biosynthesized under various conditions of pH. N. valliformis OT1 strain (A); S. palmae OF1 strain (B); S. palmae OF2 strain (C); S. alkaliphilus IF19 strain (D). 


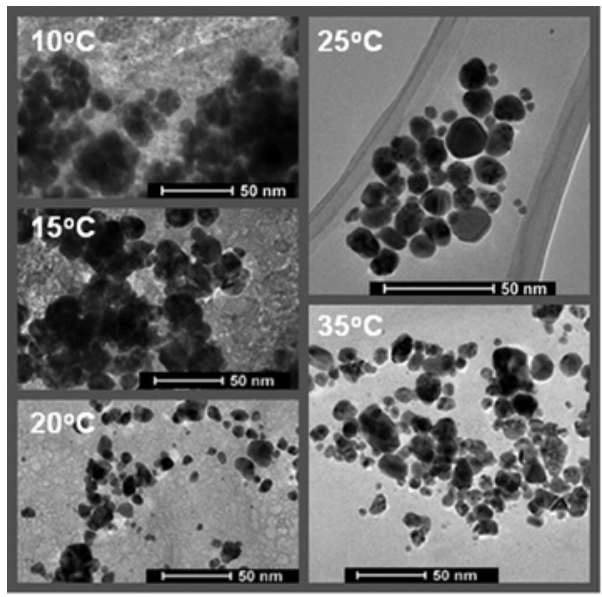

A

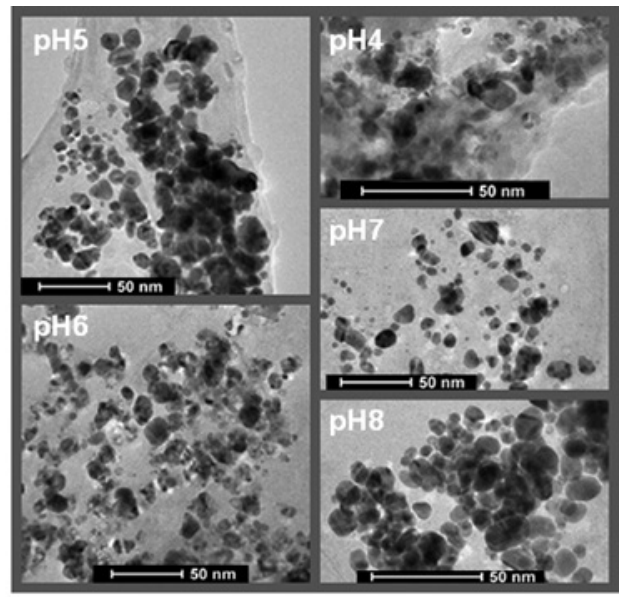

B

Figure 4: TEM analyses of AgNPs synthesized at different $\mathrm{pH}$ and temperature by using $N$. valliformis OT1 strain. Synthesis at different temperatures (A), synthesis at different $\mathrm{pH}(\mathrm{B})$.

(24, 48 and $72 \mathrm{~h}$ ) and under different temperatures (10, 15, 20, 25 and $\left.35^{\circ} \mathrm{C}\right)$ and $\mathrm{pH}(4,5,6,7$ and 8$)$ was evaluated based on their dry mass. The dry mass of AgNPs collected from $100 \mathrm{ml}$ of experimental sample was found to be 0.0 , 3.2, 6.6 and 1.0, 2.5, 3.2, 7.0, 6.0 and 2.0, 2.3, 4.0, 8.0, 8.7 mg, respectively.

\subsection{Physical properties of AgNPs synthe- sized from $N$. valliformis OT1 strain under various synthesis conditions}

The results of TEM measurements of NPs synthesized from $N$. valliformis OT1 strain under various conditions of temperature are presented in Figure 4. It was found that at temperatures below $25^{\circ} \mathrm{C}$, NPs of irregular shape and bigger size were formed and showed a tendency to form aggregates. The higher aggregation of biosynthesized AgNPs was also observed after synthesis at $35^{\circ} \mathrm{C}$. The spherical and smaller NPs were formed when synthesis process was performed at $25^{\circ} \mathrm{C}$. The average size of AgNPs biosynthesized under different temperatures is presented in Table 1.

The TEM analyses of AgNPs synthesized at different $\mathrm{pH}$ revealed that an increase in $\mathrm{pH}$ value resulted in the fabrication of smaller and more spherical NPs. The results of the TEM imaging confirmed those obtained from the absorption spectra. AgNPs synthesized at $\mathrm{pH}$ below and above neutral were irregular in shape and able to form numerous aggregates (Figure 4, Table 1). The formation of aggregates was also confirmed by NTA analysis when the biosynthesis process was performed at a $\mathrm{pH}$ value other than 7 (Table 1). The average size of AgNPs fabricated at different $\mathrm{pH}$ is presented in Table 1 .

Table 1: Effect of different $\mathrm{pH}$ and temperatures on size of AgNPs synthesized from $N$. valliformis OT1 strain.

\begin{tabular}{lcrl}
\hline Influent factor & Mean size of AgNPs by TEM $(\mathbf{n m})$ & Mean size of AgNPs by NTA $(\mathrm{nm})$ & Zeta potential $(\mathrm{mV})$ \\
\hline $\mathrm{pH}$ & & & \\
4 & 23.2 & $194.4 \pm 48.6$ & -26.6 \\
5 & 20.3 & $157.7 \pm 54.1$ & -14.6 \\
6 & 18.7 & $83.3 \pm 39.0$ & -21.4 \\
7 & 13.9 & $62.0 \pm 51.0$ & -26.2 \\
8 & 25.4 & $168.8 \pm 66.5$ & \\
Temperature $\left({ }^{\circ} \mathrm{C}\right)$ & & & -28.7 \\
10 & 32.6 & $153.3 \pm 39.3$ & \\
15 & 35.1 & $143.8 \pm 73.0$ & \\
20 & 17.1 & $145.4 \pm 136.4$ & -21.4 \\
25 & 16.5 & $62.0 \pm 51.0$ & -15.0 \\
35 & 29.8 & $179.3 \pm 57.8$ & -17.1 \\
\hline
\end{tabular}


The zeta potential values of AgNPs synthesized from $N$. valliformis OT1 strain showed their varied stability and are presented in Table 1.

\section{Discussion}

The biological synthesis of nanomaterials offers better manipulation and control over crystal growth and their stabilization. This has led to an upsurge in research on the synthesis routes that allow better control of size and shape for a wide variety of nanotechnological applications [13, 28, 29].

In the present study, the effect of temperature, time, $\mathrm{pH}$, incubation time and substrate concentration on the formation of NPs with desired properties such as the shape, size and distribution was considered.

The solution of experimental samples, in contrast to the control samples, was found to be intensified along with the increase in temperature, $\mathrm{pH}$ and incubation time that was associated with an increase in the yield of the synthesized NPs. The change in color occurs due to the excitation of free electrons in NPs, which generates the SPR. Due to SPR, a strong absorption of electromagnetic waves is exhibited by metal NPs in the visible range $[14,30]$. The SPR phenomenon arises when NPs are irradiated with visible light, because of the collective oscillations of the conduction electrons [31]. It is well known that AgNPs exhibit a yellowish-brown color in aqueous solutions due to the excitation of the SPR band in the region [32]. An increase in the intensity of the absorbance peak with time indicates the continued reduction of the silver ions and an increase in the concentration of AgNPs [1, 33]. In the present study, an effect of duration on the synthesis of AgNPs was noticed. The longer duration of time for the synthesis resulted in a higher yield of fabricated NPs. Similar observations were reported by Amin et al. [34] and Darroudi et al. [35], who studied the synthesis of AgNPs by green approach. These authors showed that the intensity of an absorption band increased along with the duration of synthesis.

One of the interesting criteria is increasing bandwidth of resonance with the decrease in the dimensions of the particles as a result of electron scattering induction at the surface. Resonance shifting and the variation of its bandwidth are important information for NP characterization [1]. The position of the absorption peak in the visible absorption spectrum of colloidal solutions can be related to the particle size and shape due to the resonance through SPR [36, 37]. It is claimed that the sharp narrow absorption peaks at lower wavelength region indicates the formation of smaller NPs [37].
Temperature is the basic physical factor that affects the formation of NPs as well as their shape and size [13]. In the present study, the intensity of peak maximum increases with increasing temperature, along with the shift in peak wavelength. The temperature of $25^{\circ} \mathrm{C}$ was the optimal temperature for the biosynthesis of AgNPs by test strain, which was confirmed by estimation of dry mass of AgNPs. Along with the decline in temperature, the absorption peaks decreased. It suggests the low concentration of biosynthesized NPs in solutions. The smallest particles were formed at optimal temperature $\left(25^{\circ} \mathrm{C}\right)$, while below and above this value, a tendency to form bigger NPS and aggregates was observed. The increase in the average size of gold and iron oxide NPs, along with the increase in temperature, was reported by other researchers [14, 38]. They suggested that it can be due to the higher activity of reducer enzymes at high temperature [14, 38]. In contrast, Verma and Mehata [39] reported that the size of the synthesized NPs decreases with an increase in temperature value. These authors claimed that it may be due to the faster reaction rate at higher temperatures. At high temperatures, the kinetic energy of the molecules increases and silver ions are consumed faster; thus, there is a possibility of decreased particle size growth. Quester et al. [40] studied the biosynthesis of AgNPs using the fungal extract of Neurospora crassa and observed the formation of smaller NPs (1-6 nm) when both temperature and $\mathrm{pH}$ values were low $\left(4^{\circ} \mathrm{C}\right.$ and $\left.\mathrm{pH} 3\right)$, while at $25^{\circ} \mathrm{C}$ and $\mathrm{pH} 6$ or 10, bigger NPs were formed (1-10 and 1-13 nm, respectively).

The important parameter that affects the synthesis, shape and size of NPs is the $\mathrm{pH}$ of the reaction solution. This factor has the ability to alter the charge of biomolecules, which may have effect on their capping as well as stabilizing properties [39].

It was found that as the $\mathrm{pH}$ value increased, the surface plasmon peak shifted to the left, indicating a decrease in the size of the prepared NPs. Moreover, this shift in the peak accompanied the decrease in the width of the peak, indicating size uniformity [12]. However, Verma and Mehata [39] showed that the shift in the peak wavelength indicates that the size of the particles increases with increasing $\mathrm{pH}$ of the solution. As the diameter of the particles get larger, the energy required for excitation of surface plasmon electrons decreases, as a result the absorption maximum shifts toward the longer wavelength region.

The present study demonstrated that the absorption intensity and amount of biosynthesized AgNPs increase along with the increase in $\mathrm{pH}$ value. Similar observations were reported by Sathishkumar and colleagues [41], who observed that a higher amount of AgNPs from Cinnamon 
zeylanicum bark extract was produced when the $\mathrm{pH}$ value of plant extract was higher than $\mathrm{pH}$ 5. Verma and Mehata [39] observed that $\mathrm{pH} 13$ was the most favorable for the synthesis of AgNPs by extract of neem (Azadirachta indica) leaves. However, at such high $\mathrm{pH}$, the NPs became unstable and agglomerated. In the present study, the AgNPs were slightly bigger in size and irregular in shape and exhibited greater tendency to form aggregates when the $\mathrm{pH}$ of the solution was lower than neutral. The tendency of AgNP agglomeration at $\mathrm{pH}>7$ was also recorded in our research. Alqadi and coauthors [12] who studied the $\mathrm{pH}$ effect on the aggregation of AgNPs synthesized by chemical reduction observed that NPs prepared under lower $\mathrm{pH}$ (7, 8 and 8.5) were mostly irregular in shape, while those formed at higher $\mathrm{pH}$ (10 and 11) were more regular and smaller. It was suggested that the irregularity in the shape of particles could be attributed to the slow reduction rate of the silver ions. Similar observations were also noted by other authors, for example Barabadi et al. [14] and Honary et al. [38], who studied fungal mediated preparation of gold and iron oxide NPs by using Penicillium crustosum and Penicillium waksmanii, respectively, and optimization of synthesis process by using mathematical methodology. The authors reported that the increase in the $\mathrm{pH}$ value of the solution significantly affected the average size of iron oxide and gold NPs. With the increase in the $\mathrm{pH}$ of the solution, the average size of NPs decreased [14, 38].

Moreover, the reducing and stabilizing agents such as diastase [16], tyrosine [15] and polyphenols of plant extracts [18] may affect the synthesis and size of the NPs of noble metals such as silver and gold. The biosynthesis process and size of NPs can be controllable by the change in $\mathrm{pH}$ of the enzyme or amino acid. It is well known that alkaline $\mathrm{pH}$ favors to improve the reduction potential of molecules containing several carboxylic groups [42]. Thus, the use of varied $\mathrm{pH}$ of diastase and tyrosine affects the synthesis and size of NPs. The authors showed that the smallest NPs of silver and gold were formed at $\mathrm{pH} 12$, and the use of $\mathrm{pH}$ of diastase below 10 influences the aggregation of AgNPs with complete precipitation at $\mathrm{pH} 8$ [17]. Similar results were observed when tyrosine mediated synthesis of AgNPs was performed [15].

The concentration of salt used for biological synthesis of NPs is an important parameter for the optimization of NP formation [19]. The authors found that out of the different concentrations of $\mathrm{AgNO}_{3}$ that they tested (0.0004, 0.0008, 0.0012, 0.0016 and $0.0024 \mathrm{~mol}$ $\left.\mathrm{l}^{-1}\right), 0.0016 \mathrm{~mol} \mathrm{l}^{-1} \mathrm{AgNO}_{3}$ was the optimum concentration required for the synthesis of AgNPs. In the present study, the use of $0.001 \mathrm{~mol} \mathrm{l}^{-1}$ concentration of $\mathrm{AgNO}_{3}$ was found to be more efficient than $0.003 \mathrm{~mol} \mathrm{l}^{-1}$ for biological synthesis of AgNPs. Other authors also found that on increasing concentration of salts used for the synthesis of gold $\left(\mathrm{AuCl}_{4}\right)$ and iron oxide $\left(\mathrm{FeCl}_{3}\right) \mathrm{NPs}$, the average size decreased but began to increase at higher concentrations. The authors suggested that the increased concentration of salt level allowed particle growth at a faster rate and that particles may aggregate in higher salt concentrations [14, 38]. Maddinedi et al. [16] also found that a reduction in the size of gold NPs (AuNPs) was obtained with an increase in the quantity of diastase as a reducing agent. The authors explained that at a low quantity of diastase, the rate of nucleation was much higher, while the rate of coating of AuNPs with diastase was less, which resulted in the formation of bigger NPs. As the quantity of diastase increased, the rate of coating also increases when compared with nucleation rate, resulting in the formation of smaller NPs [16]. Maddinedi et al. [18] found that a higher volume of water extract of Cinnamonium tsoi leaf rich in polyphenols as a reducing agent for the preparation of $\mathrm{AgNPs}$ resulted in a higher reduction rate of $\mathrm{AgNO}_{3}$ to AgNPs formation.

It is well known that the stability and size of NPs are the main properties that affect their antimicrobial efficacy. Non-agglomerated and smaller NPs are desired for antimicrobial applications as they interact better with pathogenic bacteria and fungi [43].

\section{Conclusions}

The present study demonstrated the effect of different parameters on the biosynthesis of NPs synthesized from acinobacterial strains. The formation of AgNPs as well as their physical properties depended on reaction time, temperature $\mathrm{pH}$ and reactant concentration. It was found that the size and shape of the synthesized NPs can be altered by changing these parameters. Moreover, optimal temperature $\left(25^{\circ} \mathrm{C}\right)$ and $\mathrm{pH}(7.0)$ required for synthesis of AgNPs were confluent with the optimal growth conditions of actinobacteria used for the synthesis of NPs, suggesting that bacterial enzymes could be involved in this process.

Acknowledgments: This study was funded by grants 2016/23/N/NZ9/00247 and 2017/01/X/NZ8/00140, Funder Id: $10.13039 / 501100004281$ from the National Science Centre (NCN) as well as by grant no. 2844-B from Nicolaus Copernicus University. 
Conflict of interest statement: The authors have no commercial or financial conflict of interest to declare.

\section{References}

[1] AbdelRahim K, Mahmoud SY, Ali AM, Almaary KS, Mustafa AE, Husseiny SM. Saudi J. Biol. Sci. 2017, 24, 208-216.

[2] Qin X, Lu W, Luo Y, Chang G, Sun X. Electrochem. Commun. 2011, 13, 785-787.

[3] Zhang Y, Wang L, Tian J, Li H, Luo Y, Sun X. Langmuir 2011, 27, 2170-2175.

[4] Barabadi H, Ovais M, Shinwari ZK, Saravanan M. Green. Chem. Lett. 2017, 10, 285-314.

[5] Khan I, Saeed K, Khan I. Arabian J. Chem. 2017, doi. org/10.1016/j.arabjc.2017.05.011.

[6] Gandhi H, Khan S. J. Nanomed. Nanotechnol. 2016, 7, 1-3.

[7] Golińska P, Wypij M, Ingle AP, Gupta I, Dahm H, Rai M. Appl. Microbiol. Biotechnol. 2014, 98, 8083-8097.

[8] Khan AU, Malik N, Khan M, Cho MH, Khan MM. Bioprocess Biosyst. Eng. 2018, 41, 1-20.

[9] Neihaya HZ, Zaman HH. Microb. Pathog. 2018, 16, 200-208.

[10] Wypij M, Czarnecka J, Świecimska M, Dahm H, Rai M, Golinska P. World J. Microbiol. Biotechnol. 2018, 34, 23-35.

[11] Yasir M, Singh J, Tripathi MK, Singh P, Shrivastava R. Pharmacogn. Mag. 2018, 4, 840-844.

[12] Alqadi MK, Abo Noqtah OA, Alzoubi FY, Alzouby J, Aljarrah K. Mater. Sci. Poland 2014, 32, 107-111.

[13] Prasad R. J. Nanoparticles 2014, 2014, 1-8.

[14] Barabadi H, Honary S, Ebrahimi P, Mahammadi MA, Alizadeh A, Naghibi F. Brazilian J. Microbiol. 2014, 45, 1493-1501.

[15] Maddinedi SB, Mandal BK, Anna KK. Environ. Toxicol. Pharmacol. 2017, 51, 23-29.

[16] Maddinedi SB, Mandal BK, Ranjan S, Dasgupta N. RCS. Adv. 2015, 5, 26727-26733.

[17] Maddinedi SB, Mandal BK, Anna KK. Environ. Toxicol. Pharmacol. 2017, 49, 131-136.

[18] Maddinedi SB, Mandal BK, Maddili SK. J. Photochem. Photobiol. B: Biology 2017, 167, 236-241.

[19] Subbaiya R, Saravanan M, Priya AR, Shankar KR, Selvam M, Ovais M, Balajee R, Barabadi H. IET Nanobiotechnol. 2017, 11, 965-972.

[20] Xie J, Zheng Y, Ying JY. J. Am. Chem. Soc. 2009, 131, 888-889.
[21] Rathod D, Golinska P, Wypij M, Dahm H, Rai M. Med. Microbiol. Immunol. 2016, 205, 435-447.

[22] Küster E, Williams ST. Nature 1964, 202, 928-929.

[23] Golińska P, Wypij M, Rathod D, Dahm H, Rai M. J. Basic Microbiol. 2015, 55, 1-16.

[24] Shirling EB, Gottlieb D. Int. J. Syst. Bacteriol. 1966, 16, 313-340.

[25] Atlas, RM, Ed., Handbook of Microbiological Media, 4th ed., CRC Press: Boston, 2010.

[26] Wypij M, Golinska P, Dahm H, Rai M. IET Nanobiotechnol. 2017, 11, 336-342.

[27] Yoon SH, Ha SM, Kwon S, Lim J, Kim Y, Seo H, Chun J. Int. J. Syst. Evol. Microbiol. 2017, 67, 1613-1617.

[28] Saifuddin N, Wong CW, Yasumira AAN. E-J Chem. 2009, 6, 61-70.

[29] Verma VC, Kharwar RN, Gange AC. Nanomedicine 2010, 5, 33-40.

[30] Roy K, Biswas S, Banaejee PC. Res. J. Phar. Bio. Chem. Sci. 2013, 4, 1271-1278.

[31] Samanta S, Sarkar P, Pyne S, Prasad Sahoo G, Misra A. J. Mol. Liq. 2012, 165, 21-26.

[32] Parameshwaran R, Kalaiselvam S, Jayavel R. Mat. Chem. Phys. 2013, 140, 135-147.

[33] Birla S, Gaikwad S, Gade A, Rai M. Sci. World J. 2013, 2013, 1-12.

[34] Amin M, Anwar F, Janjua MRSA, Iqbal MA, Rashid U. Int. J. Mol. Sci. 2012, 13, 9923-9941.

[35] Darroudi M, Ahmad MB, Zamiri R, Zak AK, Abdullah AH, Ibrahim NA. Int. J. Nanomedicine 2011, 6, 677-681.

[36] Durán N, Marcato PD, Alves OL, Souza GI, Esposito E. J. Nanobiotechnol. 2005, 3, 8.

[37] Ibrahim HM. J. Radiat. Res. Appl. Sci. 2015, 8, 265-275.

[38] Honary S, Barabadi H, Ebrahimi P, Naghibi F, Alizadeh A. J. Nano. Res. 2015, 30, 106-115.

[39] Verma A, Mehata MS. J. Radiat. Res. Appl. Sci. 2016, 9, 109-115.

[40] Quester K, Avalos-Borja M, Castro-Longoria E. J. Biomater. Nanobiotechnol. 2016, 7, 118-125.

[41] Sathishkumar M, Sneha K, Won SW, Cho CW, Kim S, Yun S. Coll. Surf. B: Biointerfaces 2009, 73, 332-338.

[42] Ashraf S, Abbasi AZ, Pfeiffer C, Hussain SZ, Khalid ZM, Gil PR, Parak WJ, Hussain I. Coll. Surf. B: Biointerfaces 2013, 102, 511-518.

[43] Morones JR, Elechiguerra JL, Camacho A, Holt K. Nanotechnology $2005,16,2346-2353$. 